\title{
A Modular Heat-Shrink-Packaged Check Valve With High Pressure Shutoff
}

\author{
Ronalee Lo and Ellis Meng, Senior Member, IEEE
}

\begin{abstract}
A novel check valve featuring adhesiveless packaging in heat-shrink tubing and dual regulation of in-plane flow is presented. The modular design enables simple replacement of valve components to modify valve behavior and performance. The specific design is intended for low-profile fluidic applications requiring flow control, such as drug delivery devices. The heat-shrink packaging scheme is extremely robust and can withstand $>2000 \mathrm{mmHg}(266.6 \mathrm{kPa})$ without leakage. Three different valve geometries were investigated and evaluated with theoretical and finite-element modeling analyses. Repeated flow regulation experiments on a fully packaged, hydrated valve demonstrated flow regulation between 25 and $2000 \mathrm{mmHg}(3.33-266.6 \mathrm{kPa})$ and leak-free closure up to $500 \mathrm{mmHg}(66.7 \mathrm{kPa})$ of reverse pressure with no observed stiction. The valve closing time constants were also determined.

[2011-0064]
\end{abstract}

Index Terms-Check valve, drug delivery, dual regulation, heat-shrink tubing.

\section{INTRODUCTION}

A DVANCES IN the area of microelectromechanical systems (MEMS) devices for drug delivery are of particular interest due to their potential advantages over current state-ofthe-art technology. These devices may provide greater temporal and spatial control of drug delivery at therapeutic levels directly to a target location [1]. Advanced drug delivery devices feature flow regulation which is commonly achieved by inclusion of a valve. Valves improve safety by enabling accurate control of dosing (e.g., prevention of diffusion of the drug into the body and accidental dosing) and elimination of backflow of bodily fluids into the device.

Existing MEMS-enabled drug delivery devices utilize microvalves in conjunction with other microfluidic components such as micropumps, microreservoirs, and microchannels to form complete systems. Discrete and continuous dosing or a combination of both is possible. Santini et al. presented a drugfilled microreservoir array in which individual reservoirs were selectively opened to provide discrete doses [2]. Chen and Wise developed a neural probe device capable of chemical delivery

Manuscript received March 3, 2011; revised July 18, 2011; accepted July 20, 2011. Date of publication September 1, 2011; date of current version September 30, 2011. This work was supported in part by NIH/NEI under Award R21EY018490 and in part by a Wallace H. Coulter Foundation Early Career Translational Research Award. Subject Editor C.-J. Kim.

R. Lo was with the Department of Biomedical Engineering, University of Southern California, Los Angeles, CA 90089 USA. She is now with Exponent, Menlo Park, CA 94025 USA (e-mail: rlo@usc.edu).

E. Meng is with the Departments of Biomedical and Electrical Engineering, University of Southern California, Los Angeles, CA 90089 USA (e-mail: ellis.meng@usc.edu).

Color versions of one or more of the figures in this paper are available online at http://ieeexplore.ieee.org.

Digital Object Identifier 10.1109/JMEMS.2011.2163301

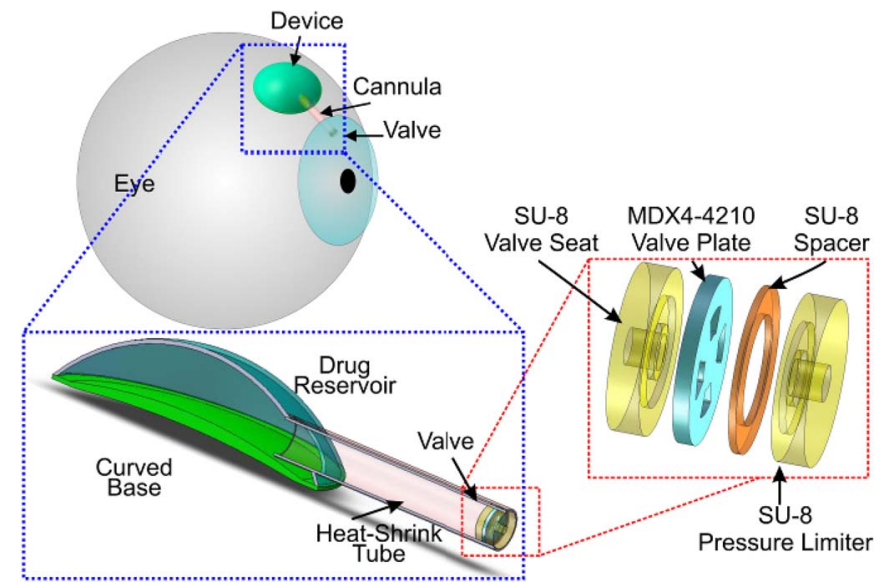

Fig. 1. A MEMS ocular drug delivery device, which is sutured to the eye, contains a refillable drug reservoir, contoured morphology, cannula, and modular valve. The valve comprises four stacked disks (valve seat, valve plate, spacer plate, and pressure limiter. The cannula is inserted into the anterior or posterior segments of the eye for targeted delivery of drugs. (Modified from [4].) copyright IEEE).

on the cellular level [3]. Cao et al. presented a drug delivery system having three piezoelectrically actuated pumping chambers to drive drug flow under a peristaltic operation principle. Each pump doubled as a normally closed valve when turned off.

In particular, MEMS are well-suited for ocular drug delivery applications. Ocular delivery constraints, such as: 1) the space limitations of the eye and its surrounding tissues; 2) physiological barriers to the target area; and 3) precise dosing control to achieve therapeutic levels, point to MEMS-based drug delivery components and devices as an attractive approach to overcome the challenges associated with current treatment methods.

Chronic ocular diseases, such as glaucoma, are currently managed by one or more of the following methods: topically and orally administered medications, injections (periocular or intraocular), and biodegradable drug implants. The drug administration mode must provide therapeutic drug levels by overcoming physiological barriers while simultaneously being safe and minimally invasive. Additionally, the method must address chronic delivery for long-term treatment of incurable diseases [4]. Topical and oral methods suffer from severe side effects due to systemic absorption while frequent injections may result in tissue trauma. These methods have poor patient acceptance and compliance. Current drug delivery implants have limited payloads. A MEMS approach to refillable ocular drug delivery provides targeted and accurate dosing to the anterior chamber of the eye while overcoming these limitations (Fig. 1). 


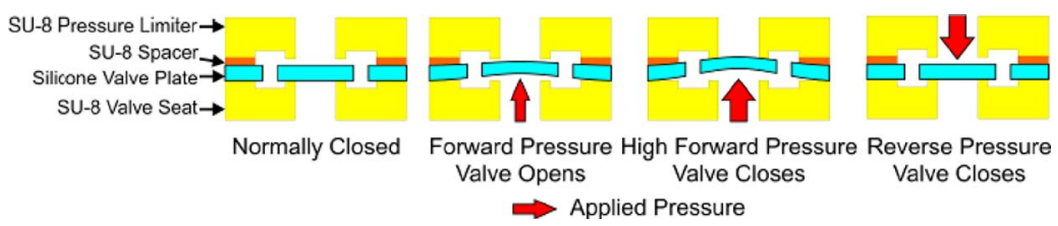

Fig. 2. Valve operation (from left to right): initially the normally closed valve opens under forward pressure that exceeds cracking pressure, excessive pressures close the valve, and the valve remains closed under reverse pressure.

Presented here is a dual regulation check valve which will be incorporated into a refillable MEMS ocular drug delivery system. The system comprises a refillable drug reservoir, electrolysis pump, cannula, a dual regulation check valve, and refill port. Electrolysis actuation drives drug from within the device reservoir into the eye. The reservoir stores sufficient drug for delivery over several months $(\sim 50 \mu \mathrm{L})$; the specific drug regimen (dose volume and dosing frequency) varies with drug and disease and is determined by an ophthalmologist. Once the volume of drug has been depleted, a 30 gauge noncoring needle can be used to refill the drug reservoir via a refill port.

The cannula and check valve can provide targeted delivery to the anterior or posterior segment of the eye. The current target application is glaucoma treatment which affects the tissues in the anterior chamber of the eye. Accordingly, the cannula is inserted into the anterior chamber via a small incision in the sclera, a portion of the eye wall. The device reservoir is sutured to the eye and completely covered by the outer portion of the eye wall (conjunctiva) to prevent infection. In the rabbit model, the cannula extends $3 \mathrm{~mm}$ into the anterior chamber.

We previously reported a drug delivery system consisting of a refillable silicone drug reservoir, flexible Parylene $\mathrm{C}$ cannula, and electrolysis pump [5]. Drug was pumped directly into the eye by electrolysis actuation. However, this prototype lacked a flow control valve; drugs and bodily fluids could readily diffuse into and out of the device through the cannula. Furthermore, the delicate, thin-walled Parylene $\mathrm{C}$ cannula was easily damaged during surgical manipulation and implantation. Its rectangular profile made it difficult to seal the incision through which it was inserted with sutures alone; leakage paths were often present at the interface between the cannula and incision site. Therefore, a more robust, circular cannula with an integrated check valve was developed.

A cannula having circular cross section facilitates wound closure with sutures and prevents leakage around the incision. Ideally, the cannula diameter is $<1 \mathrm{~mm}$; an incision of this size in the eyewall can self-seal even without the use of sutures. Therefore, the valve design should accommodate a circular cannula. Additionally, the valve must be in-plane with respect to the fluid flow. This ensures that that moving mechanical parts of the valve do not come in contact with ocular tissues [6]. This valve orientation also minimizes dead-volume. To prevent diffusion of drug from the device into the tissue, the valve must be normally closed. Finally, the valve must be safe and function reliably under normal intraocular pressure (IOP) conditions $[15.5 \pm 2.6 \mathrm{mmHg}, 2.1 \pm 0.35 \mathrm{kPa}$, (mean $\pm \mathrm{SD}$ )] [7], elevated conditions (glaucoma IOP $>22 \mathrm{mmHg}, 2.9 \mathrm{kPa}$ ), and transient pressures fluctuations (e.g., patient sneezing, eye rubbing, or changes in ambient pressure) [7], [8]. In summary, the specifications of the packaged valve are: 1) outer diameter
$<1 \mathrm{~mm}$; 2) valve cracking pressure $>22 \mathrm{mmHg}$ (normal IOP maximum value); and 3) valve closure for large and sudden pressure spikes to prevent accidental dosing. Therefore, "bandpass" regulation of flow is desirable. The precise high pressure shutoff specification is currently unknown and will be determined in planned in vivo experiments.

Many MEMS valves have been developed and were reviewed recently by Oh and Ahn [9]. To minimize the power requirements for the ocular drug delivery device, only passive mechanical valve designs were considered. These valves allow flow under forward pressure and exhibit diode-like regulation of flow. Examples include valves consisting of flow orifices controlled by pressure-sensitive flaps, membranes, and spherical balls. Lin et al. presented a glaucoma drainage device with Parylene $\mathrm{C}$ check valves (normally closed and normally open) in series to achieve bandpass regulation. Adhesives were used to secure the valves in a Parylene C tube [10]. Lo et al. fabricated a normally closed silicone valve within a rectangular cannula by stacking patterned layers of silicone rubber [4]. However, current valve designs and packaging schemes are not suitable for integration into an advanced ocular drug delivery device; therefore, a new valve and package are necessary.

Our valve approach is modular and consists of four plates stacked together to form a normally closed valve with a pressure limiter feature to provide bandpass fluid regulation [4]. The four plates are the valve seat, valve plate, spacer plate, and pressure limiter. Each of these plates can be replaced or exchanged for a different plate design. The normally closed valve opens under an applied pressure greater than the cracking pressure. At the cracking pressure, the valve plate deflects away from the valve seat such that a flow path forms between them to allow forward fluid flow. Valve plate deflection increases with pressure and eventually, at a pressure exceeding the closing pressure, the soft silicone rubber valve plate seals against the rigid pressure limiter to stop flow through the valve altogether. Thus, the "bandpass"-like behavior cuts off flow to prevent accidental dosing when unanticipated excessive forward pressures occur (Fig. 2).

To simplify the packaging processes and to increase the yield, no adhesives were used. Instead, our approach utilizes biocompatible heat-shrink tubing as a packaging material for our valve. Here, the heat-shrink tube also serves as the drug delivery cannula. Heat-shrink tubing has been widely used in electronics for applications such as electrical isolation, environmental protection, repair, and strengthening of joints. Heatshrink tubes are available in many thermoplastic materials, such as polyolefin, fluoropolymer (fluorinated ethylene propylene (FEP), polytetrafluoroethylene, polyvinylidene fluoride), polyvinyl chloride, neoprene, and silicone elastomer. The heatshrink mechanism is achieved by first forming the material into 


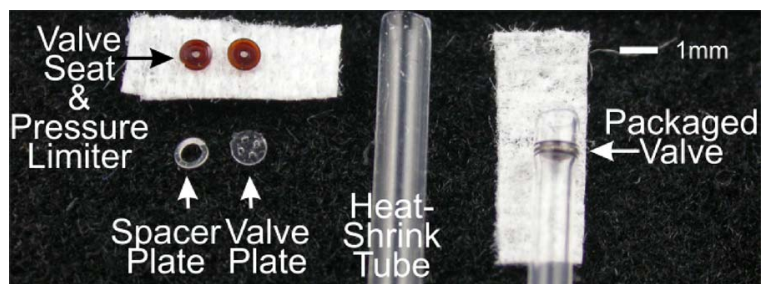

Fig. 3. Photo of the valve components (valve seat, valve plate, spacer plate, and pressure limiter), heat-shrink tube prior to thermally-assisted shrinking, and fully assembled valve. (Modified from [4].)

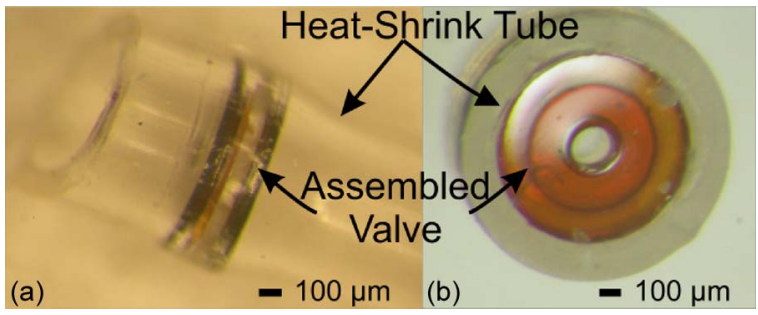

Fig. 4. (a) Side view and (b) top view of the packaged valve in a FEP heatshrink tube. The valve was placed inside the tube with a custom jig. The entire fixture was heated to $215^{\circ} \mathrm{C}$ at $1.5^{\circ} \mathrm{C} / \mathrm{min}$ and cooled at the same rate to room temperature [4].

its final shape. Then, ionizing radiation is used to cross-link the material. Once cross-linked, the part is heated above the melting temperature. The part is then stretched or blown into an expanded configuration and cooled to maintain the expanded state. The part will then shrink when heat, near the melting point, is again applied to the part due to the elastic nature of the cross-linked material [11]. Biocompatible heat-shrink tubing (polyolefin) was investigated as a packaging scheme for flexible sensors [12] and glaucoma drainage implants [13]. Due to its conformal nature, circular shape, and biocompatibility, heat-shrink tubing was selected for packaging the valve for the ocular drug delivery application.

\section{Device Design}

\section{A. Design}

The four modular valve components are shown in Fig. 3 along with the heat-shrink tubing. The valve seat and valve plate form the normally closed portion of the valve. The SU- 8 spacer plate defines the distance the valve plate must deflect to seal against the pressure limiter plate. Therefore, the thickness of the spacer plate, in part, controls the pressure at which the valve closes. The valve seat and pressure limiter provide the structural support for the valve plate.

The valve plate is fabricated using medical-grade silicone. SU-8 was chosen for the valve seat and spacer plate due to its ease of fabrication and larger Young's modulus compared to silicone rubber. SU-8's biocompatibility has been investigated, and reduced biofouling compared to silicon was demonstrated [14]. Other medical-grade polymers can also be used to replace the SU-8 components.

The assembled valve is packaged into a $22 \mathrm{G}$ FEP heat-shrink tube (Zeus Industrial Products Inc., Orangeburg, SC) (Fig. 4). FEP is a well-known medical material and is designated a USP class VI biocompatible polymer. FEP is also transparent,

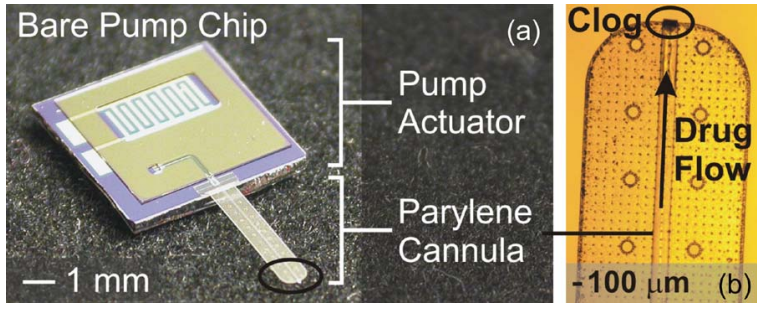

Fig. 5. Photo of (a) Parylene $\mathrm{C}$ cannula integrated with a drug delivery pump and (b) clogging of Parylene $\mathrm{C}$ cannula after ex vivo testing.

with a refractive index of 1.338 [15], thereby allowing visual inspection of the valve after packaging. FEP is resistant to most chemicals and solvents and can withstand temperatures in excess of $260{ }^{\circ} \mathrm{C}$, making it suitable for a wide range of applications.

Upon heating, the heat-shrink tube contracts around the valve stack forming a robust package that securely holds the valve assembly in place without any adhesives. The SU-8 plates surrounding the silicone rubber valve plate prevent significant radial stress on the valve plate.However, this heat-shrink packaging method does impose an axial compression on the outer circular perimeter valve plate, which translates into a compression of the components in the entire valve stack. This gives rise to a finite cracking pressure. The previous Parylene $\mathrm{C}$ cannula was prone to clogging or damage during surgical implantation (Fig. 5); therefore, a more robust cannula design was necessary. The heat-shrink tube wall thickness (approximately $200 \mu \mathrm{m}$ ) is greater than that of the Parylene C cannula (thickness $7.5 \mu \mathrm{m}$ ), resulting in a more mechanically robust structure. As mentioned previously, the circular cannula facilitates sealing of the incision, thereby minimizing leakage at the cannula and tissue interface.

\section{B. Theory}

The valve diameter was dictated by surgical requirements; a maximum incision length of $1 \mathrm{~mm}$ was permitted. Therefore, valve components were limited to $900 \mu \mathrm{m}$ in diameter, leaving $100 \mu \mathrm{m}$ for packaging. The dimensions and geometry of the individual valve components were determined using theoretical equations and finite-element modeling.

The analytical solution for large deflection of a flexible plate of uniform thickness guided selection of the thicknesses of the spacer and valve plates [(1) and (2)]. The maximum deflection $\left(w_{\max }\right)$ of a uniform and homogenous place was calculated from the plate thickness $(t)$, applied pressure $(p)$, plate radius $(a)$, and flexural rigidity $(D)$. Flexural rigidity is a function of Young's modulus $(E)$, plate thickness $(t)$, and Poisson's ratio $(\nu)[16]$.

$$
\begin{aligned}
w_{\max }\left(1+0.486 \frac{w_{\max }^{2}}{t^{2}}\right) & =\frac{p a^{4}}{64 D} \\
D & =\frac{E t^{3}}{12\left(1-\nu^{2}\right)} .
\end{aligned}
$$

The outer edge ( $150 \mu \mathrm{m}$ wide band) of the valve plate was reserved for clamping by the valve seat and pressure limiter, leaving a $600 \mu \mathrm{m}$ diameter area for the active deflecting area of 
TABLE I

SumMaRy of VALUES USED in THEORETICAL CALCULATIONS OF LARGE DEFORMATIONS IN UNIFORM THIN PLATES

\begin{tabular}{lc}
\hline Variable & Value \\
\hline Thickness $(t)$ & $0-150 \mu \mathrm{m}$ \\
Applied Pressure $(p)$ & $0-1000 \mathrm{mmHg}, 0-133.3 \mathrm{kPa}$ \\
Plate Radius $(a)$ & $300 \mu \mathrm{m}$ \\
Young's Modulus $(E)$ & $2 \mathrm{MPa}$ \\
Poisson's Ratio $(v)$ & 0.48 \\
\hline
\end{tabular}

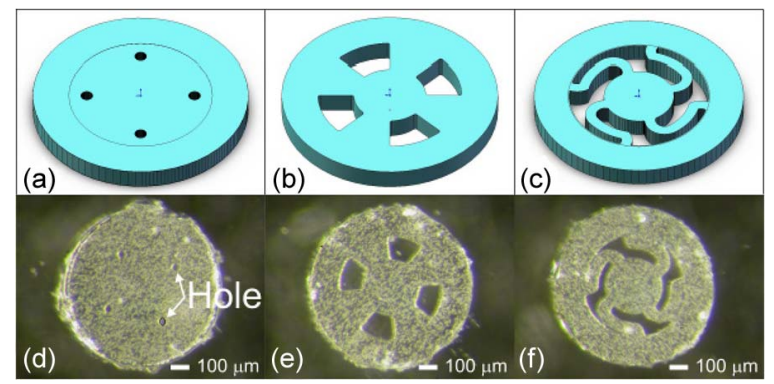

Fig. 6. Three different valve plate designs (a) hole, (b) straight arm, and (c) s-shape arm ([4], copyright IEEE); and the corresponding fabricated silicone rubber valve plates (d) hole (through holes are indicated by the arrows), (e) straight-arm, and (f) s-shaped arm.

the plate. In the analysis, applied pressure was varied between 0 and $1000 \mathrm{mmHg}(0$ and $133.3 \mathrm{kPa})$ and applied to valve thicknesses between 0 and $150 \mu \mathrm{m}$. The resulting calculated $w_{\max }$ was assigned as the maximum thickness of the spacer plate. It should be noted that $w_{\max }$ is the deflection at the center of the plate; sealing against the pressure limiter requires greater deflection. The final values were chosen based on estimated pressure operating ranges and ease of handling. The values used in the large-deflection equations are shown in Table I. This model, however, does not account for the prestress exerted by the heat-shrink packaging nor the presence of IOP in the eye. The IOP of the eye exerts a constant reverse pressure on the valve plate on the order of $15.5 \pm 2.6 \mathrm{mmHg}$ [7].

\section{Finite-Element Modeling}

SolidWorks models of the valve components were created for finite-element modeling (FEM) analyses. Stress and deformation FEM analyses determined the stress distribution and valve behavior for forward pressure values ranging from 0 to $1000 \mathrm{mmHg}$ ( 0 to $133.3 \mathrm{kPa}$ ), and the reverse pressure value of $-500 \mathrm{mmHg}(66.7 \mathrm{kPa})$. FEM results provided convenient visualization of valve plate movements and its interaction with the pressure limiter.

Three different valve plate designs (hole, straight arm, and s-shape arm) were investigated (Fig. 6). Each design possessed a different effective fluidic resistance and thus differing bandpass flow regulating characteristics (e.g., opening and closing pressure). FEM estimations and theoretical analyses guided the assignment of valve geometries such that the operational pressure range would be limited at the lower bound by normal IOP, $<35 \mathrm{mmHg}$ (4.7 $\mathrm{kPa})$, and an upper bound that was arbitrarily chosen to be at least two orders of magnitude greater than normal IOP values (e.g., $2000 \mathrm{mmHg}, 266.6 \mathrm{kPa}$ ). However, the operating pressure ranges of the valve are easily customized by
TABLE II

Dimensions of VALVE COMPONENTS, INCLUding THE ThreE Different Valve Designs (Hole, Straight Arm, S-Shape Arm). VAlve Materials (MDX4-4210 AND SU-8) ARE BIOCOMPATIBLE. All COMPONENTS ARE $900 \mu \mathrm{m}$ IN DiAMETER

\begin{tabular}{|c|c|c|c|c|c|}
\hline Piece & 3-D Model & Top View & Side View & Material & Thickness \\
\hline $\begin{array}{c}\text { Pressure } \\
\text { Limiter }\end{array}$ & $x+10$ & & $\square-\square$ & SU-8 & $200 \mu \mathrm{m}$ \\
\hline $\begin{array}{l}\text { Spacer } \\
\text { Plate }\end{array}$ & & & $=\quad=$ & SU-8 & $40 \mu \mathrm{m}$ \\
\hline $\begin{array}{l}\text { Valve } \\
\text { Plate }\end{array}$ & & & ロロロ & MDX4-4210 & $75 \mu \mathrm{m}$ \\
\hline $\begin{array}{l}\text { Valve } \\
\text { Seat }\end{array}$ & $\pi$ & & 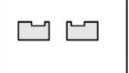 & SU-8 & $200 \mu \mathrm{m}$ \\
\hline
\end{tabular}

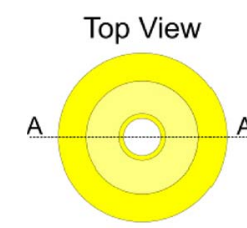

(a)

(b)

(c)
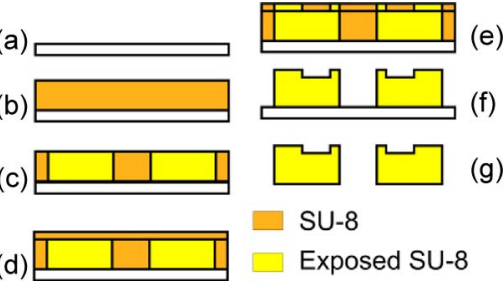

(d)

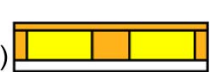

Exposed SU-8

Fig. 7. Fabrication process for the valve seat and pressure limiter plates. Fabrication steps are cross-section views at the $\mathrm{A}-\mathrm{A}^{\prime}$ line. (Modified from [4].)

altering the dimensions of the valve plate and spacer plate. The dimensions of the valve components are presented in Table II.

The operating characteristics of the valve are easily modified to adapt the valve for other uses such as alternate drug delivery applications. Theoretical equations and FEM deflection simulations show that adjustments to the valve plate or spacer plate dimensions will affect the bandpass region of the valve behavior. Increasing the valve plate diameter, reducing the valve plate thickness, creating more compliant tethers in the valve plate, using a more flexible material for the valve plate, or using a thinner spacer plate will narrow the bandpass region by lowering the closing pressure value. Adding a bossed structure to the bottom of the valve plate can also narrow the bandpass region by increasing the cracking pressure.

\section{FABRICATION AND PACKAGING}

\section{A. SU-8 Valve Seat and Pressure Limiter}

The SU-8 valve seat and pressure limiter shared identical designs. This choice simplified fabrication and ensured interchangeability of the two parts. A two-layer SU-8 process was used (Fig. 7). First, a soda-lime wafer (Mark Optics, Santa Ana, CA) was dehydrated for $20 \mathrm{~min}$ at $120^{\circ} \mathrm{C}$. Then, the wafer was treated with Omnicoat (MicroChem, Newton, MA) to facilitate release of the SU-8 components. Three layers of Omnicoat were spun onto the wafer ( $3000 \mathrm{rpm}, 30 \mathrm{~s})$ with a bake step $\left(1 \mathrm{~min}\right.$ at $\left.200{ }^{\circ} \mathrm{C}\right)$ performed after each coat [Fig. 7(a)]. Multiple Omnicoat layers reduced the time and temperature required for the release step. SU-8 2100 (MicroChem, Newton, MA) was prespun onto the wafer $(30 \mathrm{~s}, 500 \mathrm{rpm})$ to provide an even coating. Then, $160 \mu \mathrm{m}$ SU-8 was applied (30 s, 


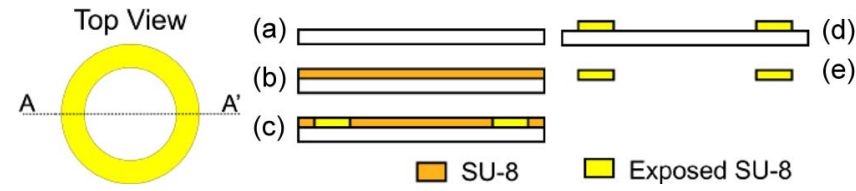

Fig. 8. Fabrication process for the SU-8 spacer plate. Fabrication steps are cross-section views at the A-A' line. (Modified from [4].)

$1750 \mathrm{rpm}$ ) to form the first layer of the component [Fig. 7(b)]. This layer was softbaked on a hotplate at $95{ }^{\circ} \mathrm{C}$ for $2 \mathrm{~h}$ (temperature ramped at $3{ }^{\circ} \mathrm{C} / \mathrm{min}$ ) and slowly cooled to room temperature. The layer was then patterned $\left(390 \mathrm{~mJ} / \mathrm{cm}^{2}\right)$; the energy dosage was determined by using the suggested energy level for $160 \mu \mathrm{m}\left(260 \mathrm{~mJ} / \mathrm{cm}^{2}\right)$ and adjusting with a $1.5 \mathrm{mul}-$ tiplier for using a glass substrate instead of silicon [Fig. 7(c)]. Dicing saw tape was placed behind the wafer prior to exposure to prevent unwanted exposure from the reflected UV from the aligner chuck. A postexposure bake $\left(12 \mathrm{~min}, 95^{\circ} \mathrm{C}\right)$ was completed, again ramping from room temperature to $95{ }^{\circ} \mathrm{C}$ at $3{ }^{\circ} \mathrm{C} / \mathrm{min}$ and slowly cooling back to room temperature. $40 \mu \mathrm{m}$ of SU-8 2050 (MicroChem, Newton, MA) was spin coated $(30 \mathrm{~s}, 4000 \mathrm{rpm})$ to form the features in the valve seat and pressure limiter [Fig. 7(d)]. The wafer was then baked for $3 \mathrm{~h}$ at $95^{\circ} \mathrm{C}$ (with ramp up and cool down). The $40 \mu \mathrm{m}$ was patterned $\left(192 \mathrm{~mJ} / \mathrm{cm}^{2} ; 160 \mathrm{~mJ} / \mathrm{cm}^{2}\right.$ times a 1.2 multiplier for a SU-8 substrate), and postexposure baked for $14 \mathrm{~min}$ at $95^{\circ} \mathrm{C}$ [Fig. 7(e)]. The components were developed using SU-8 developer (MicroChem, Newton, MA) [Fig. 7(f)].

To remove the valve seats and pressure limiters from the wafer, the wafer was immersed in Remover PG (MicroChem, Newton, MA) [Fig. 7(g)]. The components were rinsed in isopropyl alcohol, IPA, and DI $\mathrm{H}_{2} \mathrm{O}$ and then hardbaked at $215^{\circ} \mathrm{C}$ for $1 \mathrm{~h}$. The hardbake step annealed the SU-8 components to improve thermal resistance for the subsequent heat-shrink packaging process. Hardbaking was performed in an air environment; however, discoloration of the SU-8 parts resulted which may be attributed to oxidation. Discoloration of the valve seat (dark orange) resulting from hardbaking in air can be seen in Figs. 3 and 4. This was consistent with other reports in literature in which the threshold for the discoloration reaction occurred between 200 and $250{ }^{\circ} \mathrm{C}$ when baked in air whereas SU-8 baked in vacuum exhibited no discoloration up to $300{ }^{\circ} \mathrm{C}$ [17], [18]. Thus, the hardbake process was modified and performed under vacuum to prevent discoloration of the SU-8 and reduce the residual stress in the thick film structure [17]. Finally, this separate hardbake step was removed to simplify the fabrication process; the entire assembled valve was hardbaked during the heat-shrink tubing process (heat-shrink packaging was performed under vacuum at $215^{\circ} \mathrm{C}$ ).

\section{B. SU-8 Spacer}

The spacer plate was fabricated on a dehydrated wafer $\left(20 \mathrm{~min}, 120^{\circ} \mathrm{C}\right.$ ) coated with three layers of Omnicoat (as described in the fabrication of the valve seat and pressure limiter) [Fig. 8(a)]. The $40 \mu \mathrm{m}$ thick spacer plate was spin coated (SU-8 2050, 30 s, 4000 rpm) [Fig. 8(b)]. The layer was softbaked at $95{ }^{\circ} \mathrm{C}$ for $1 \mathrm{~h}$, ramping at $3{ }^{\circ} \mathrm{C} / \mathrm{min}$ from room temper-

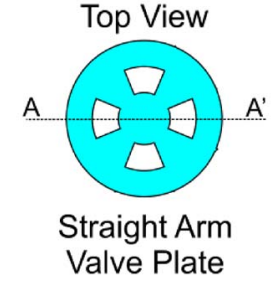

(a)

(b)

(c)

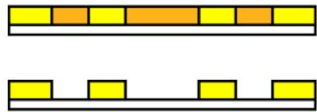

(d)

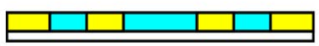

(e)

SU-8 $\square$ Exposed SU-8 Silicone (MDX4-4210)

Fig. 9. Fabrication process for the valve plate using an SU-8 master mold. Fabrication steps are cross-section views at the A-A' line. (Modified from [4].)

ature to $95{ }^{\circ} \mathrm{C}$. Dicing saw tape was applied to the backside of the wafer prior to exposure $\left(240 \mathrm{~mJ} / \mathrm{cm}^{2} ; 160 \mathrm{~mJ} / \mathrm{cm}^{2}\right.$ times a 1.5 multiplier for a glass substrate) [Fig. 8(c)]. The wafer was immersed in SU-8 developer [Fig. 8(d)]. The spacer plates were then released from the substrate using Remover PG and rinsed using IPA and DI $\mathrm{H}_{2} \mathrm{O}$ [Fig. 8(e)].

\section{Silicone Valve Plate}

The valve plate was fabricated by casting medical grade silicone pre-polymer (MDX4-4210, Dow Corning, Midland, MI) on a SU-8 master mold. The SU-8 master was created on a soda lime wafer using SU-8 2050. First, the wafer was treated with A-174 (a silane adhesion promoter) to enhance Parylene C adhesion to the soda lime wafer. A $4 \mu \mathrm{m}$ layer of Parylene C (Specialty Coating Systems, Inc., Indianapolis, IN) was vapor deposited onto the wafer to prevent the SU-8 from delaminating from the wafer due to mismatch of the thermal coefficients of expansion between soda lime and SU-8 [5]. A $75 \mu \mathrm{m}$ layer of SU-8 2050 was spin coated (30 s, $2000 \mathrm{rpm}$ ) and softbaked for $90 \mathrm{~min}$ at $95{ }^{\circ} \mathrm{C}$ [Fig. 9(a)]. This layer of SU-8 defined the valve plate thickness. The SU-8 layer was patterned $\left(308 \mathrm{~mJ} / \mathrm{cm}^{2} ; 208 \mathrm{~mJ} / \mathrm{cm}^{2}\right.$ dose times a 1.5 multiplier for the glass substrate) and developed using SU-8 developer [Fig. 9(b) and (c)]. MDX4-4210 (10:1 base to curing agent ratio), was poured onto the mold and degassed under vacuum. Excess silicone was removed by scraping the mold with a metal squeegee [Fig. 9(d)] [19]. Valve plates were released from the mold; any excess silicone was manually removed using a finetipped blade [Fig. 9(e)].

\section{Heat-Shrink Packaging}

Valves were assembled by stacking individual components. First, the components were gathered onto a silicone sheet under a stereo microscope. Silicone provided a tacky surface to hold the stack steady while making alignment adjustments.

First, the valve seat was placed face up (sealing rings up) on the silicone working space [Fig. 10(a)]. Next, the valve plate was stacked on top [Fig. 10(b)]. The valve plate must be aligned such that none of the through holes are placed over the valve seat opening. Misalignment may compromise the normally closed function of the valve, or prevent the valve from closing at elevated pressures. The spacer plate was added on top of the valve plate, again, ensuring that the spacer plate was aligned and not covering the valve plate through holes 


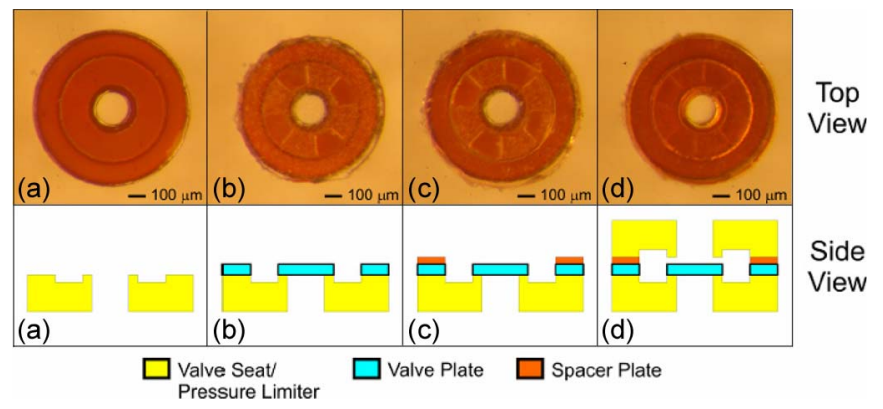

Fig. 10. Top and side views of valve assembly. (a) Valve seat. (b) Valve plate added to valve seat. (c) Spacer plate placed on valve plate. (d) Pressure limiter added to assembled valve.

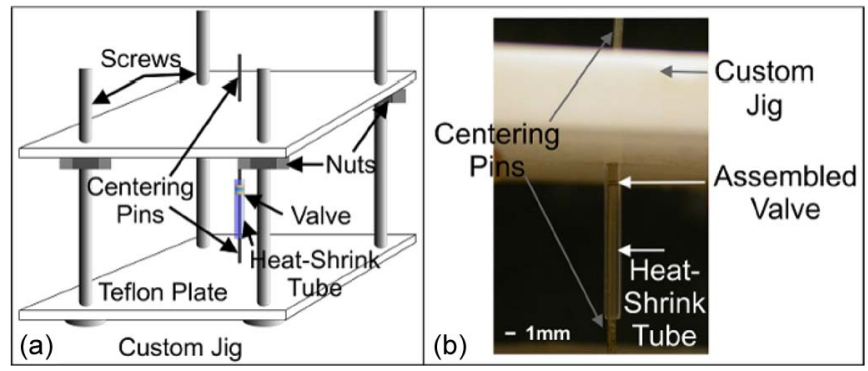

Fig. 11. (a) Heat-shrink jig setup showing Teflon base and top each contain a centering pin. The top and base are aligned with machine screws. Nuts set the separation between the top and base. (b) Close up view of an assembled valve with heat-shrink tube surrounding the valve prior to thermal treatment.

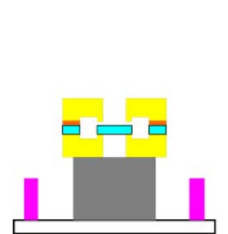

(a)
Assemble valve on jig Put heat-shrink around valve

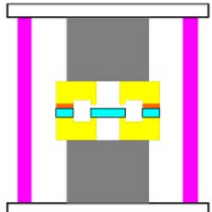

b)

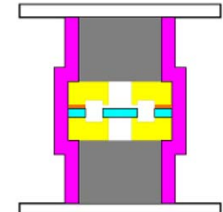

(c)

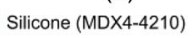

Place setup in oven $\left(215^{\circ} \mathrm{C}\right)$

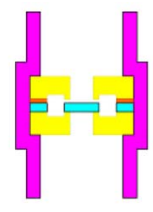

(d)

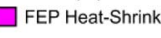

Remove setup from jig
Fig. 12. Process steps to package assembled valve. (a) FEP heat-shrink tube is placed around bottom centering pin, assembled valve is placed on centering pin, (b) jig top is added, valve is clamped between top and bottom centering pins, FEP tube is lifted around valve, (c) jig and valve assembly is placed in vacuum oven, and (d) packaged valve is removed from jig. (Modified from [4].)

[Fig. 10(c)]. Finally, the bottom side of the pressure limiter, the side with the sealing rings, was identified and placed face down on top of the spacer plate [Fig. 10(d)].

The assembled valve was then packaged in $1.3: 1$ shrink ratio FEP heat-shrink tubing with the aid of a custom Teflon jig containing stainless steel centering pins ( $813 \mu$ m diameter) [Fig. 11(a) and (b)]. A 22G (inner diameter prior to shrinkage: $914 \mu \mathrm{m}$, maximum wall thickness: $254 \mu \mathrm{m}$ ) heat-shrink tube was placed around the centering pin on the jig base. The heatshrink tube must be shorter than the centering pin. Next, the assembled valve (valve seat, valve plate, spacer plate, pressure limiter) was carefully placed on the centering pin [Fig. 12(a)]. The jig top, which has a matching and adjustable stainless steel centering pin, was aligned and secured to the jig base using four machine screws. The distance between the jig base and top was set using nuts positioned along the screws. The two centering pins were aligned, and the top pin was slowly

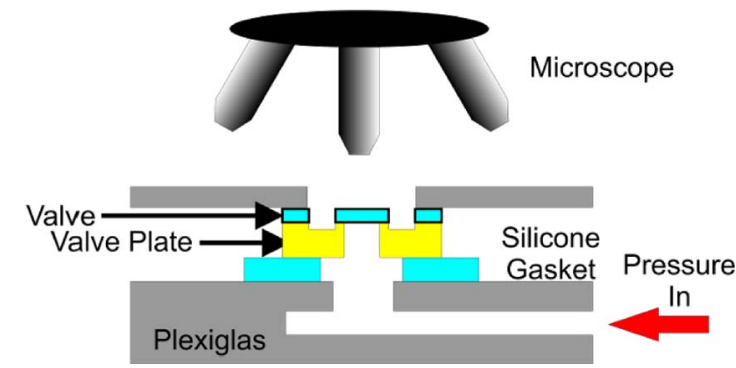

Fig. 13. Valve plate deflection setup.

lowered until the valve stack was securely clamped. The FEP tubing was carefully slipped around the valve [Figs. 11(b) and 12(b)]. The entire jig was then placed in a vacuum oven and heated to $215{ }^{\circ} \mathrm{C}$ at a rate of $1.5^{\circ} \mathrm{C} / \mathrm{min}$, held at $215^{\circ} \mathrm{C}$ for at least $30 \mathrm{~min}$, and then cooled to room temperature at the same rate [Fig. 12(c)]. The baking and cooling steps were ramped to limit the thermally induced stress on SU-8 which may lead to cracking. The jig was removed from the oven and disassembled. Then, the packaged valve was slipped off the centering pins [Fig. 12(d)].

\section{Experimental Methods}

\section{A. Valve Plate Deflection}

The deflection for each valve plate design (hole, straightarm, s-shaped arm) under forward pressure was measured and compared to theoretical values for large deflection of a uniform plate ((1) and (2)). Each plate was clamped at the periphery in a custom-made jig which allowed pressurized air to be applied to the backside (Fig. 13). Plate deflection was measured using a compound microscope with $1 \mu \mathrm{m}$ resolution. The microscope was focused on the center of the valve plate under zero applied pressure. Pressurized nitrogen gas $(0-500 \mathrm{mmHg}, 0-66.7 \mathrm{kPa})$ was applied to deflect valve plate. The microscope was refocused on the center of the deflected plate, and deflection was calculated from the change in the microscope fine focus knob position ( $1 \mu \mathrm{m}$ resolution).

\section{B. Heat-Shrink Packaging Characterization}

The heat-shrink packaging method was evaluated to determine the dimensional changes during the thermal shrinking process, the robustness of the package, and the fluidic integrity. Two different gauges (22G and 18G) of FEP heat shrink were characterized. The outer diameters of preshrink and postshrunk tubing were compared, and the percent change in outer diameter was calculated. The fluidic integrity of each tube was quantified by packaging a solid $200 \mu \mathrm{m}$ thick SU-8 disk. A $900 \mu \mathrm{m}$ diameter disk was used in the $22 \mathrm{G}$ tube; the solid disk possesses the same diameter as the individual valve components. The $18 \mathrm{G}$ tube was packaged with a $1.5 \mathrm{~mm}$ diameter disk for comparison. The solid disks were packaged under the same conditions as the valve (room temperature to $215{ }^{\circ} \mathrm{C}$ at $\leq 1.5^{\circ} \mathrm{C} / \mathrm{min}$ and cooled from $215{ }^{\circ} \mathrm{C}$ to room temperature at $\leq 1.5^{\circ} \mathrm{C} / \mathrm{min}$ ) (Fig. 14).

Both pressurized water and nitrogen gas $(0-2000 \mathrm{mmHg}$, 0-266.6 kPa) were applied through the heat-shrink tube against 


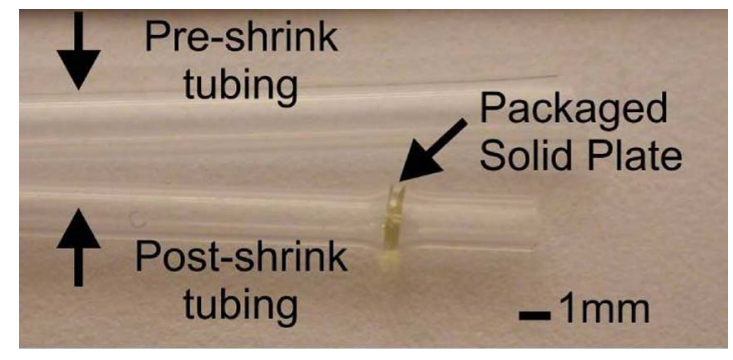

Fig. 14. Pre- and postheat-shrink tubing. Solid disk packaged in heat-shrink tubing to test robustness of the adhesiveless packaging method.

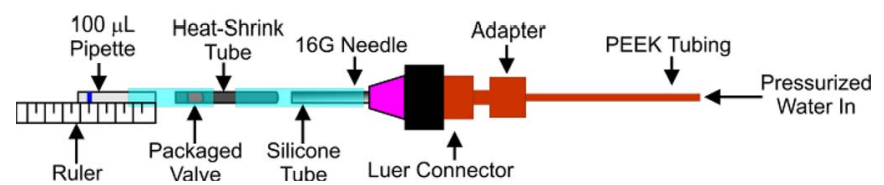

Fig. 15. Test setup to determine valve operating characteristics.

one side of the solid disk. A $100 \mu \mathrm{L}$ calibrated pipette (Clay Adams, Parsippany, NJ, USA) was placed at the outlet to measure leakage of water between the disk and heat-shrink tubing. For pressurized $\mathrm{N}_{2}$, the tubing outlet was immersed in water to visualize any bubbles due to leakage.

\section{Packaged Valve Characterization}

The bandpass flow regulation behavior of a packaged valve (hole valve plate) was determined (Fig. 15). Pressurized water $(0-1000 \mathrm{mmHg}, 0-133.3 \mathrm{kPa})$ was applied in incremental steps to the valve inlet. The flow rate from the packaged valve was measured using a $100 \mu \mathrm{L}$ calibrated pipette connected to the outlet. The pipette was prefilled with double distilled water and a bubble was introduced between the valve outlet and pipette inlet to facilitate flow measurement. The system was held at each test pressure setpoint for $3 \mathrm{~min}$ to allow the system to equilibrate. The cracking pressure and flow rates for different pressures were measured. Reverse pressure $(0-500 \mathrm{mmHg}$, 0-66.7 kPa) was also investigated. Several flow profiles (flow rate versus pressure) for a hydrated valve (valve that was kept in contact with water at all times) were obtained to verify repeatability of valve operation. The hydrated valve data was also compared to a dry valve (valve where water was allowed to evaporate between experiments).

The closing time constant for the valve was determined by applying pressurized water $(250,500$, and $750 \mathrm{mmHg} ; 33.3$, 66.6 , and $100 \mathrm{kPa}$, respectively) to the valve, shutting off the pressure with a pneumatic solenoid valve, and measuring the accumulated volume of water exiting the valve after pressure shut-off. A circuit controlled the pneumatic solenoid valve, and a light-emitting diode was used to indicate the solenoid valve state (open or closed). Closing time was defined as the duration between the elapsed time from pressure shut-off to when $63.2 \%$ of the total accumulated volume had exited the valve.

\section{RESUlts AND DisCUSSION}

\section{A. Valve Plate Deflection}

The experimentally obtained valve plate deflection for each valve plate design was compared to theoretical values (Fig. 16)

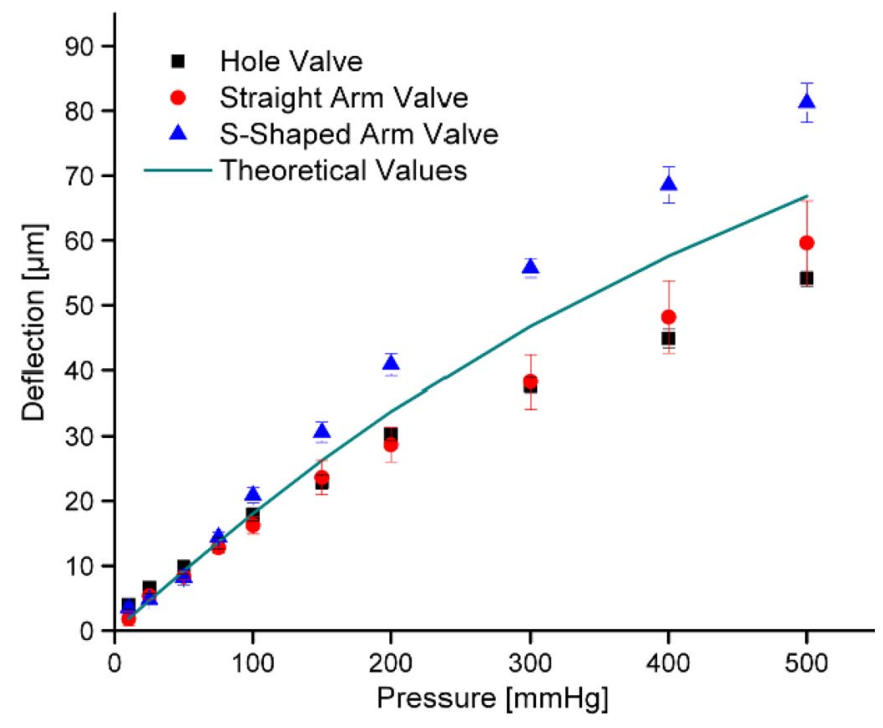

Fig. 16. Comparison of measured valve plate deflection to the theoretical values for a flat plate [4].

and found to be in agreement. While the theoretical model did not completely predict the behavior, it still provided useful insight on valve design. Deviations from the measured data could be attributed to the geometrical differences from the theoretical thin plate geometry. The plate thickness used in the equation was $75 \mu \mathrm{m}$, whereas the fabricated valve plates were slightly thicker at $84 \pm 3.7 \mu \mathrm{m}, 87.8 \pm 5.3 \mu \mathrm{m}$, and $82.2 \pm$ $5.4 \mu \mathrm{m}$ (mean $\pm \mathrm{SE}, n=4$ ) for the hole, straight arm, and s-shaped arm valve plates, respectively. A thicker plate generally leads to less deflection. However, changing the geometry from a flat plate to a selectively perforated plate increased achievable vertical deflection due to increased flexibility. Thus, the straight-arm valve plate deflected more than the hole design even though the straight-arm plates were slightly thicker. The clearest demonstration of the impact of tether compliance on achievable deflection was the s-shaped arm valves. The s-shaped tethers bend allowing the plate to twist upward and away from the valve seat as pressure is applied, providing additional deflection [20]. Therefore, the s-shaped arm valve plate achieved the greatest deflection for a given applied pressure.

\section{B. Finite-Element Analyses}

Finite-element analyses of displacement and stress were conducted on an assembled hole valve (Table III). A linear FEM model with small-displacement conditions was used to provide a qualitative understanding of valve behavior. The effect of radial strain from the heat-shrink package on the flexible valve plate and the presence of IOP were not included in the model. The 22AWG heat-shrink tubing O.D. change at the valve was minimal (a $4.65 \%$ decrease in size). Furthermore, the $200 \mu \mathrm{m}$ rigid SU-8 valve seat and pressure limiter support the valve stack and prevent buckling. However, a finite axial strain is present on the outer circular periphery of the valve plate and expected to contribute to the finite cracking pressure encountered in actual valve operation along with IOP.

As the applied pressure on the valve plate increased in the model, displacement and stress values also increased. The valve 
TABLE III

Summary of THE FEM RESUlts FOr Displacement AND STRESS ON an Assembled Valve. (Modified From[4].)

\begin{tabular}{|c|c|c|}
\hline Pressure & Displacement & Stress \\
\hline$-500 \mathrm{mmHg}$ & & \\
\hline $100 \mathrm{mmHg}$ & & \\
\hline $500 \mathrm{mmHg}$ & & \\
\hline \multirow[t]{2}{*}{$1000 \mathrm{mmHg}$} & & \\
\hline & $58.5 \mu \mathrm{m}$ & $988.4 \mathrm{kPa}$ \\
\hline
\end{tabular}

plate deflected until it was constrained by the pressure limiter and eventually sealed. However, the center of the valve plate continued to deflect with increasing pressure, albeit in smaller increments. Under reverse pressure application, the valve plate deflected $<7 \mu \mathrm{m}$ and maintained an effective seal against the valve seat.

The stress analysis provided guidance on the selection of suitable materials on the basis of mechanical robustness. At the maximum forward applied pressure $(1000 \mathrm{mmHg}, 133.3 \mathrm{kPa})$, stress accumulated in the bottom of the valve seat and valve plate. The maximum stress was experienced by the valve plate $(0.99 \mathrm{MPa})$ and was concentrated along the edge in contact with the valve seat. The observed stress was $<20 \%$ of MDX4-4210 tensile strength (5 $\mathrm{MPa}$ ) and significantly less than the tensile strength of SU-8 (60 MPa). Reverse pressure $(500 \mathrm{mmHg}$, $66.7 \mathrm{kPa})$ analysis verified that the induced stresses $(0.46 \mathrm{MPa})$ were at least an order of magnitude less than the tensile stresses of MDX4-4210 or SU-8.

\section{Heat-Shrink Package Characterization}

The final postshrink diameter for the 22G FEP cannula used to package the valve was approximately $1 \mathrm{~mm}$. The outer diameter of the heat-shrink tube decreased 19.4-25\% postshrinkage in areas adjacent to the valve stack. In the valve region, shrinkage was reduced $(4.65 \%)$ and the diameter was slightly greater than $1 \mathrm{~mm}$. This slight increase in diameter does not compromise the incision site which must be sealed around the cannula alone and not the valved portion.

A segment of heat-shrink tube was packaged with a solid SU-8 disk to determine the robustness of the packaging method and the quality of the seal around object. For both the 18 and $22 \mathrm{G}$ tubes, the solid disks remained in position under applied pressure and the entire system was leak-tight up to $2000 \mathrm{mmHg}$ $(266.6 \mathrm{kPa})$ of pressurized water. This value is the pressure limit of our testing apparatus and almost two orders of magnitude greater than normal IOP values. The packaged system was also able to withstand up to $2000 \mathrm{mmHg}(266.6 \mathrm{kPa})$ of pressurized nitrogen gas as verified by the absence of bubbles while submerged under water. The maximum pressure for microfluidic
TABLE IV

Summary of HEAT-ShrinK TUbe Characterization RESUlts FOR Two Tube Gauge Sizes (22 AWG And 18 AWG)

\begin{tabular}{|c|c|c|}
\hline $\begin{array}{l}\text { FEP Heat-Shrink } \\
\text { Characterization }\end{array}$ & $22 \mathrm{AWG}$ & $18 \mathrm{AWG}$ \\
\hline Valve O.D. [mm] & 0.9 & 1.5 \\
\hline $\begin{array}{c}\text { Initial tube O.D. }[\mathrm{mm}] \\
(\mathrm{n}=5 \text {, mean } \pm \text { SE }) \\
\text { Post-shrink O.D. }\end{array}$ & $1.29 \pm 0.014$ & $1.88 \pm 0.006$ \\
\hline $\begin{array}{c}\text { Tube + Valve }[\mathrm{mm}] \\
(\mathrm{n}=5, \text { mean } \pm \text { SE })\end{array}$ & $1.23 \pm 0.002$ & $1.84 \pm 0.004$ \\
\hline $\begin{array}{l}\text { Post-shrink O.D. } \\
\text { Tube Only }[\mathrm{mm}] \\
(\mathrm{n}=21, \text { mean } \pm \mathrm{SE})\end{array}$ & $1.04 \pm 0.006$ & $1.41 \pm 0.005$ \\
\hline$\%$ change in O.D. & $19.40 \%$ & $25 \%$ \\
\hline $\begin{array}{c}\text { Leakage Pressure } \\
{[\mathrm{mmHg}, \mathrm{kPa}]}\end{array}$ & $>2000,266.6$ & $>2000,266.6$ \\
\hline
\end{tabular}

interconnects using heat-shrink tubing also reported leak-free connections up to $200 \mathrm{kPa}$ [13]. These results are comparable to devices which are secured using adhesives [21]-[23]. A summary of the results is presented in Table IV.

In Fig. 14, the packaged solid SU-8 disk was slightly rotated with respect to the axis of the tube. When packaging single disks, it was difficult to perfectly align the disk. However, despite the rotation, the seal around the disk edge was leak-tight. When packaging the full valve, the multiple layers facilitate alignment of the stack within the tube bore. In combination with the alignment pins in the assembly fixture shown in Fig. 11, misalignment was avoided.

For the pressures of interest for the drug delivery application, compliance of the heat-shrink tubing was not observed in the heat-shrink packaging nor the valve characterization. The FEP heat-shrink tube is mechanically robust (elastic modulus of 0.44-0.64 GPa and Shore D hardness of 50-65 according to manufacturer data sheets [15]).

This characterization demonstrates that this packaging technique is extremely robust and thus suitable for a wide variety of applications. A diverse selection of materials and gauges of heat-shrink tube are commercially available and can be selected to match specific packaging needs.

\section{Packaged Valve Characterization}

The valve operating range was determined by visually observing valve operation and measuring flow rate at specific pressure setpoints. Pressurized rhodamine dye was applied to the cannula inlet and enhanced visualization of fluid flow through the valve. Rhodamine was observed to exit only at the pressure limiter through hole. No leakage at the interface between the assembled valve and heat-shrink tube was observed (Fig. 17). This demonstrates robustness of this packaging method for stacked components fabricated from different polymers.

Consistent flow rate profiles (pressure versus flow rate) were repeatedly obtained in sequential experiments when the valve remained hydrated between runs. All experimental trials were performed within a 24-h period. A representative result of the bandpass regulation with a hole valve plate is shown in Fig. 18. The hole valve cracking pressure was approximately $25-50 \mathrm{mmHg}(3.3-6.7 \mathrm{kPa})$ and the maximum flow rate $(3.18 \pm 0.18 \mu \mathrm{L} / \mathrm{sec}$, mean $\pm \mathrm{SE}, n=4)$ occurred near 


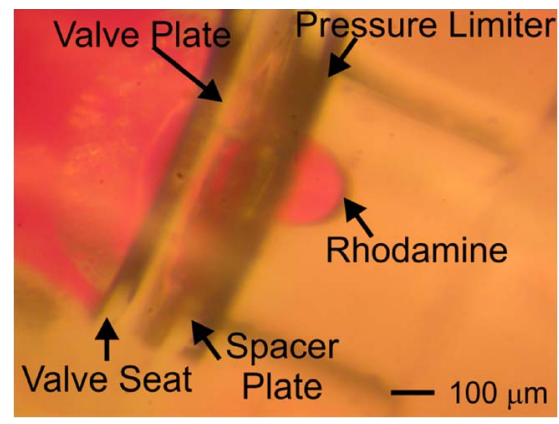

Fig. 17. Visualization of flow rate through valve using rhodamine dye.

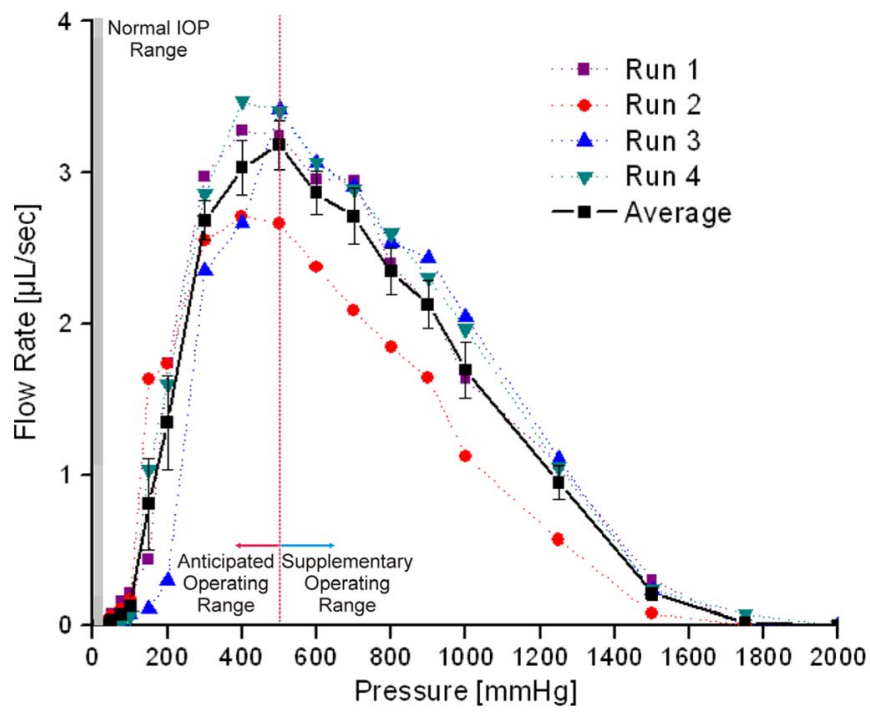

Fig. 18. Valve performance from four runs on the same packaged hole valve. The valve was kept hydrated in double distilled water between runs to prevent valve from drying out. The valve remained leak-tight up to $500 \mathrm{mmHg}$ of reverse pressure (not shown on graph). Cracking pressure between 25 and $50 \mathrm{mmHg}(3.3$ and $6.7 \mathrm{kPa})$ and closing pressures between 1750 and $2000 \mathrm{mmHg}(233.3$ and $266.6 \mathrm{kPa})$ were measured.

TABLE V

Summary of Packaged Valve (Hole, Straight Arm, and S-Shaped VALVes) OPERATING Characteristics

\begin{tabular}{lccc}
\hline $\begin{array}{l}\text { Pressure Parameter } \\
{[\mathrm{mmHg}]}\end{array}$ & Hole & $\begin{array}{c}\text { Straight } \\
\text { Arm }\end{array}$ & $\begin{array}{c}\text { S-Shaped } \\
\text { Arm }\end{array}$ \\
\hline Cracking Pressure & 50 & 300 & $100^{\mathrm{a}}$ \\
$\begin{array}{l}\text { Closing Pressure } \\
\begin{array}{l}\text { Minimum Sustained } \\
\text { Reverse Pressure }\end{array}\end{array}$ & 1750 & 900 & $700^{\mathrm{b}}$ \\
$\begin{array}{l}\text { Pressure for Max Flow } \\
\text { Rate }\end{array}$ & 500 & 500 & 500 \\
\hline
\end{tabular}

$500 \mathrm{mmHg}(66.7 \mathrm{kPa})$ (Fig. 18). The valve closed between 1750 and $2000 \mathrm{mmHg}(233.3$ and $266.6 \mathrm{kPa}$ ) and remained leak-free up to $500 \mathrm{mmHg}(66.7 \mathrm{kPa})$ of reverse pressure, which is at least an order of magnitude greater than normal IOP values (reverse pressure data not shown on graph). Stiction was not observed in hydrated valves. Also, consistent performance was observed under continuous usage.

Table V summarizes packaged valve performance for all three valve designs. As expected, the s-shaped arm closed at

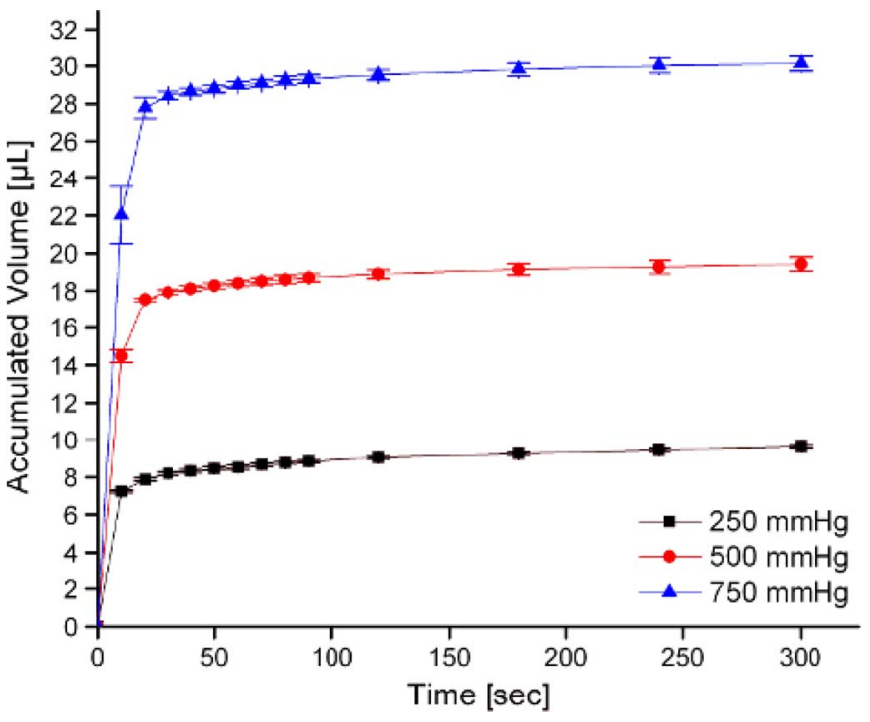

Fig. 19. Accumulated volume measurements to determine closing time constant for a packaged hole valve. Closing time constants were calculated by determining the amount of time for $63.2 \%$ of the total accumulated volume to exit the valve.

the lowest forward pressure. This agrees with the theoretical and FEM models in which s-shaped arm valve plates achieved greater deflection compared to the other two valve designs for the same applied pressure. The pressure corresponding to maximum flow rate was identical for the hole and straightarm valves since the hole and straight-arm valves have similar deflection responses for pressures between 0 and $500 \mathrm{mmHg}$ (as shown in Fig. 16).

The averaged flow rate profile (mean $\pm \mathrm{SE}, n=4$ ) was compared to that of a dried valve. For dried valves, the cracking pressure was much higher $(200-300 \mathrm{mmHg}, 26.7-40 \mathrm{kPa})$. The increase might be attributed to stiction between the valve plate and seat. Additionally, the dried valve had a smaller closing pressure (1000-1250 mmHg, 133.3-166.7 kPa). Hydration causes the silicone to swell, increasing the valve plate thickness and altering the deflection behavior; swelling could not be quantified due to the presence of the packaging. An implanted valve will remain hydrated from contact with the aqueous or vitreous humors; therefore, the hydrated flow profile is more representative of long-term valve behavior. However, this also suggests that valves may need to be preconditioned prior to implantation. Stiction was not observed for hydrated valves. It is possible to coat the silicone valve plate with Parylene $\mathrm{C}$ to avoid swelling altogether. This barrier layer also prevents drug diffusion through the porous silicone plate.

The valve has a finite response time when the applied pressure is removed. The closing time constants were determined for three different applied pressures $(250,500$, and $750 \mathrm{mmHg}$; 33.3, 66.7, and $100 \mathrm{kPa}$, respectively) (Fig. 19). These values were selected based on maximal flow rate observed near $500 \mathrm{mmHg}(66.7 \mathrm{kPa})$. An electronically controlled pneumatic valve, with a response time of $3 \mathrm{~ms}$, was used to provide a near instantaneous application and shut-off of pressure. Dispensed volume data was extracted from video footage of the flow 
TABLE VI

Summary of Closing Time Constants for the Hole Valve

\begin{tabular}{cccc}
\hline $\begin{array}{c}\text { Pressure } \\
{[\mathrm{mmHg}]} \\
([\mathrm{kPa}])\end{array}$ & $\begin{array}{c}\text { Accumulated } \\
\text { Volume }[\mu \mathrm{L}] \\
(\text { mean } \pm \mathrm{SE}, \mathrm{n}=4)\end{array}$ & $\begin{array}{c}63.2 \% \\
\text { Volume } \\
{[\mu \mathrm{L}]}\end{array}$ & $\begin{array}{c}\text { Closing Time } \\
\text { Constant } \\
{[\mathrm{sec}]}\end{array}$ \\
\hline $\begin{array}{c}250 \\
(33.3)\end{array}$ & $9.60 \pm 0.079$ & 5.98 & 7.6 \\
$\begin{array}{c}500 \\
(66.7)\end{array}$ & $19.43 \pm 0.378$ & 12.11 & 7.85 \\
$\begin{array}{c}750 \\
(100)\end{array}$ & $30.13 \pm 0.401$ & 18.77 & 8.05 \\
\hline
\end{tabular}

tracked by a bubble moving in a $100 \mu \mathrm{L}$ pipette after pressure removal. The bubble was observed for 5 min after the pressure was removed from the valve to ensure that the valve was completely closed. Accumulated volume experiments for each pressure were repeated four times. The data are summarized in Table VI.

Closing time constants were very consistent with only a slight increase in response time at higher pressures. As pressure increases, the valve plate deflects further from the valve seat and has a greater distance to travel when returning to the initial position. These results are the best case scenario of the three designs. The hole valve design is the least compliant and therefore would have the fastest response time. The other two designs, with tether designs, will have less restoring force to close the valve.

One would expect the highest accumulated volume to correspond to the highest flow rate $(500 \mathrm{mmHg}, 66.7 \mathrm{kPa})$. However, $750 \mathrm{mmHg}(100 \mathrm{kPa})$ resulted in the largest accumulated volume (Fig. 19) and is attributed to the difference between transient and steady state flow rates in the closing time and flow rate profile experiments, respectively.

The total accumulated dosage after the pressure is removed from the valve depends on the applied pressure and the amount of time the valve was pressurized (i.e., if the flow rate has reached steady state). However, the accumulated volume can affect the final dosage, particularly for small targeted values. Therefore, shorter closing times are desirable; designs to shorten the closing time can be investigated for high precision applications.

\section{CONCLUSION}

An in-plane check valve capable of bandpass fluid flow regulation and packaged within biocompatible heat-shrink tubing without the use of adhesives was designed, packaged, and tested. The valve demonstrated consistent regulation of fluid flow with a cracking pressure of $25-50 \mathrm{mmHg}(3.3-6.7 \mathrm{kPa})$ and closing pressure of $1750-2000 \mathrm{mmHg}(233.3-266.6 \mathrm{kPa})$. Peak flow through the valve, $3.18 \pm 0.18 \mu \mathrm{L} / \mathrm{sec}$, was observed at $500 \mathrm{mmHg}(66.7 \mathrm{kPa})$. The valve was able to withstand a reverse pressure of $500 \mathrm{mmHg}(66.7 \mathrm{kPa})$ without leaking or valve failure. The heat-shrink package is very robust and can withstand both water and $\mathrm{N}_{2}$ gas pressures in excess of $2000 \mathrm{mmHg}(266.6 \mathrm{kPa})$. Packaged valves were integrated into a drug delivery device surgical model; this device will be used for ex vivo and in vivo validation of valve operation.

\section{ACKNOWLEDGMENT}

The authors would like to thank Dr. D. Zhu, B. Lee, and the members of the USC Biomedical Microsystems Laboratory for their assistance with this work.

\section{REFERENCES}

[1] A. C. R. Grayson, R. S. Shawgo, A. M. Johnson, N. T. Flynn, L. I. Yawen, M. J. Cima, and R. Langer, "A BioMEMS review: MEMS technology for physiologically integrated devices," Proc. IEEE, vol. 92, no. 1, pp. 6-21, Jan. 2004.

[2] J. T. Santini, M. J. Cima, and R. Langer, "A controlled-release microchip," Nature, vol. 397, no. 6717, pp. 335-338, Jan. 28, 1999.

[3] J. K. Chen, K. D. Wise, J. F. Hetke, and S. C. Bledsoe, "A multichannel neural probe for selective chemical delivery at the cellular level," IEEE Trans. Biomed. Eng., vol. 44, no. 8, pp. 760-769, Aug. 1997.

[4] R. Lo and E. Meng, "In-plane bandpass regulation check valve in heatshrink packaging for drug delivery," in Proc. IEEE 22nd Int. Conf. Micro Electro Mech. Syst., 2009, pp. 236-239.

[5] P. Y. Li, J. Shih, R. Lo, S. Saati, R. Agrawal, M. S. Humayun, Y. C. Tai, and E. Meng, "An electrochemical intraocular drug delivery device," Sens. Actuators A, Phys., vol. 143, pp. 41-48, May 2, 2008.

[6] R. Lo, P.-Y. Li, S. Saati, R. N. Agrawal, M. S. Humayun, and E. Meng, "A passive MEMS drug delivery pump for treatment of ocular diseases," Biomed. Microdevices, vol. 11, no. 5, pp. 959-970, Oct 2009.

[7] R. Ritch, M. B. Shields, and T. Krupin, The Glaucomas, vol. 2. St. Louis, MO: Mosby, 1989.

[8] J. T. Wilensky, "The role of medical therapy in the rank order of glaucoma treatment," Curr. Opin. Ophthalmol., vol. 10, no. 2, pp. 109-111, Apr. 1999.

[9] K. W. Oh and C. H. Ahn, "A review of microvalves," J. Micromech. Microeng., vol. 16, no. 5, pp. R13-R39, May 2006.

[10] J. C.-H. Lin, P.-J. Chen, B. Yu, M. Humayun, and Y.-C. Tai, "Minimally invasive Parylene dual-valved flow drainage shunt for glaucoma implant," in Proc. IEEE 22nd Int. Conf. Micro Electro Mech. Syst., 2009, pp. 196-199.

[11] R. Bradley, Radiation Technology Handbook. New York: Marcel Dekker, 1984.

[12] J. Naito, M. Shikida, M. Hirota, Z. Y. Tan, and K. Sato, "Miniaturization of on-wall in-tube flexible thermal flow sensor using heat shrinkable tube," in Proc. IEEE Int. Conf. Micro Electro Mech. Syst., Tucson, AZ, 2008, pp. 924-927.

[13] T. Pan, J. D. Brown, and B. Ziaie, "An artificial nano-drainage implant (ANDI) for glaucoma treatment," in Proc. IEEE Eng. Med. Biol. Soc., Piscataway, NJ, 2006, pp. 3174-3177.

[14] G. Voskerician, M. S. Shive, R. S. Shawgo, H. V. Recum, J. M. Anderson, M. J. Cima, and R. Langer, "Biocompatibility and biofouling of MEMS drug delivery devices," Biomaterials, vol. 24, no. 11, pp. 1959-1967, May 2003.

[15] Zeus Industrial Products, Inc., Orangeburg, SC, FEP Resin Properties.

[16] A. C. Ugural, Stresses in Plates and Shells, 2nd ed. New York: McGraw-Hill, 1999.

[17] J. H. Daniel, B. Krusor, R. B. Apte, M. Mulato, K. V. Schuylenbergh, R. Lau, T. Do, R. A. Street, A. Goredema, D. C. Boils-Boissier, and P. M. Kazmaier, "Micro-electro-mechanical system fabrication technology applied to large area X-ray image sensor arrays," J. Vac. Sci. Technol. A, vol. 19, no. 4, pp. 1219-1223, Jul. 2001.

[18] C. D. Joye, J. P. Calame, M. Garven, and B. Levush, "UV-LIGA microfabrication of $220 \mathrm{GHz}$ sheet beam amplifier gratings with SU-8 photoresists," J. Micromech. Microeng., vol. 20, no. 12, p. 125016 , Dec. 2010.

[19] R. K. Suk, W. Xuefeng, K. Shaikh, and L. Chang, "A method for precision patterning of silicone elastomer and its applications," J. Microelectromech. Syst., vol. 13, no. 4, pp. 568-575, Aug. 2004.

[20] X.-Q. Wang, Q. Lin, and Y.-C. Tai, "A Parylene micro check valve," in Proc. 12th IEEE Int. Conf. Micro Electro Mech. Syst., 1999, pp. 177-182.

[21] E. S. Lee, D. Howard, E. Liang, S. D. Collins, and R. L. Smith, "Removable tubing interconnects for glass-based micro-fluidic systems made using ECDM," J. Micromech. Microeng., vol. 14, no. 4, pp. 535-541, Apr. 2004.

[22] A. Puntambekar and C. H. Ahn, "Self-aligning microfluidic interconnects for glass- and plastic-based microfluidic systems," J. Micromech. Microeng., vol. 12, no. 1, pp. 35-40, Jan. 2002.

[23] J. H. Tsai and L. W. Lin, "Micro-to-macro fluidic interconnectors with an integrated polymer sealant," J. Micromech. Microeng., vol. 11, no. 5, pp. 577-581, Sep. 2001. 


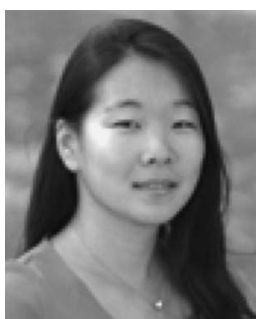

Ronalee Lo received the B.S. degree in engineering from Harvey Mudd, College Claremont, CA, in 2001, and the M.S. degree in biomedical engineering (medical devices and diagnostic engineering) and the M.S. degree in electrical engineering from the University of Southern California, Los Angeles, CA, in 2005 and 2009, respectively. She received the $\mathrm{Ph} . \mathrm{D}$. degree in 2009 from the University of Southern California Department of Biomedical Engineering, where she was a member of the Biomedical Microsystems Laboratory.

She worked at a biotechnology consulting firm, bioSTAR Group, Inc., Germantown, MD, prior to starting her graduate studies. Her research interests include bioMEMS drug delivery devices and microfluidic interconnects. She is currently working for Exponent, an engineering and scientific consulting firm.

Dr. Lo is a member of the Biomedical Engineering Society.

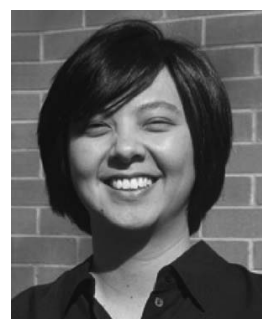

Ellis Meng (M'02-SM'09) received the B.S. degree in engineering and applied science and the M.S. and Ph.D. degrees in electrical engineering from the California Institute of Technology (Caltech), Pasadena, in 1997, 1998, and 2003, respectively.

Since 2004, she has been with the Department of Biomedical Engineering, University of Southern California (USC), Los Angeles, where she is currently an Associate Professor. She holds a joint appointment in the Ming Hsieh Department of Electrical Engineering, USC. She was the Thrust Leader for Interface Technology and the Associate Director of Education and Student Diversity Researcher at the NSF's Biomimetic Microelectronic Systems Engineering Research Center, USC. She held the Viterbi Early Career Chair in the USC Viterbi School of Engineering. Her research interests include biological microelectromechanical systems, implantable biomedical microdevices, microfluidics, multimodality integrated microsystems, and packaging.

Dr. Meng is a member of Tau Beta Pi, the Biomedical Engineering Society, the Society of Women Engineers, and the American Society for Engineering Education. She was a recipient of the Intel Women in Science and Engineering Scholarship, the Caltech Alumni Association Donald S. Clark Award, and the Caltech Special Institute Fellowship. She has also received the NSF CAREER and Wallace H. Coulter Foundation Early Career Translational Research Awards. Recently, she was selected as an innovative young engineering educator by the National Academy of Engineering. 